\title{
Cerebrovascular autoregulation and neurologic injury in neonatal hypoxic-ischemic encephalopathy
}

\author{
Jessica A. Howlett ${ }^{1,2}$, Frances J. Northington ${ }^{1,2}$, Maureen M. Gilmore ${ }^{1,2}$, Aylin Tekes ${ }^{2,3}$, Thierry A.G.M. Huisman ${ }^{2,3}$, \\ Charlamaine Parkinson 1,2, Shang-En Chung ${ }^{4,5}$, Jacky M. Jennings ${ }^{4,5}$, Jessica J. Jamrogowicz ${ }^{6}$, Abby C. Larson ${ }^{6}$, \\ Christoph U. Lehmann', Eric Jackson ${ }^{6}$, Ken M. Brady ${ }^{7}$, Raymond C. Koehler ${ }^{6}$ and Jennifer K. Lee ${ }^{2,6}$
}

BACKGROUND: Neonates with hypoxic-ischemic encephalopathy (HIE) are at risk of cerebral blood flow dysregulation. Our objective was to describe the relationship between autoregulation and neurologic injury in HIE.

METHODS: Neonates with HIE had autoregulation monitoring with the hemoglobin volume index ( $\mathrm{HVx}$ ) during therapeutic hypothermia, rewarming, and the first $6 \mathrm{~h}$ of normothermia. The 5-mm Hg range of mean arterial blood pressure (MAP) with best vasoreactivity (MAP OPT ) was identified. The percentage of time spent with MAP below MAP ${ }_{\text {OPT }}$ and deviation in MAP from $M A P_{\text {OPT }}$ were measured. Neonates received brain magnetic resonance imaging (MRI) 3-7 d after treatment. MRIs were coded as no, mild, or moderate/severe injury in five regions.

RESULTS: HVx identified MAP OPT in 79\% (19/24), 77\% (17/22), and $86 \%$ (18/21) of the neonates during hypothermia, rewarming, and normothermia, respectively. Neonates with moderate/ severe injury in paracentral gyri, white matter, basal ganglia, and thalamus spent a greater proportion of time with MAP below MAP $_{\text {OPT }}$ during rewarming than neonates with no or mild injury. Neonates with moderate/severe injury in paracentral gyri, basal ganglia, and thalamus had greater MAP deviation below MAP ${ }_{\text {OPT }}$ during rewarming than neonates without injury.

CONCLUSION: Maintaining MAP within or above MAP ${ }_{\text {OPT }}$ may reduce the risk of neurologic injuries in neonatal HIE.

$\mathrm{N}$ eonatal hypoxic-ischemic encephalopathy (HIE) affects $\sim 3$ in 1,000 births (1) and causes significant neurologic morbidity despite therapeutic hypothermia (2). Identifying modifiable factors and additional interventions may improve outcomes. The healthy brain maintains constant cerebral blood flow (CBF) across changes in blood pressure through cerebrovascular autoregulation. This physiologic mechanism functions within a specific hemodynamic range, and the term optimal mean arterial blood pressure $\left(\mathrm{MAP}_{\mathrm{OPT}}\right)$ refers to the range of MAP where cerebral vasoreactivity is most robust. That is, $\mathrm{MAP}_{\mathrm{OPT}}$ is the blood pressure range in which the cerebral vasculature has maximal pressure reactivity $(3,4)$. Neonates with HIE may be at risk of CBF dysregulation with shifts in the limits of autoregulation, particularly with intracranial hypertension (5). The hemodynamic goals that conform to the limits of autoregulation are unknown in neonatal HIE. Moreover, traditional blood pressure goals based on gestational age have not been tested against neurologic outcomes in HIE.

Traditionally, autoregulation has been monitored with transcranial Doppler or intracranial pressure $(6,7)$. However, continuous transcranial Doppler monitoring requires expertise and equipment that are not widely available, and intracranial pressure is not routinely monitored in neonates. We developed a method to monitor cerebrovascular reactivity using nearinfrared spectroscopy (NIRS): the hemoglobin volume index (HVx) (8). HVx represents the relationship between relative tissue hemoglobin (rTHb; a surrogate measure of cerebral blood volume (CBV) obtained by NIRS) and MAP. The rTHb is a trend of total hemoglobin measurements obtained by NIRS using light with a wavelength of $805 \mathrm{~nm}$. Because the $805-\mathrm{nm}$ wavelength is isosbestic to both oxyhemoglobin and deoxyhemoglobin, rTHb is not affected by fluctuations in oxygen saturation. $\mathrm{HVx}$ is based on the premise that autoregulatory vasoconstriction and vasodilation induce changes in CBV that are proportional to changes in $\mathrm{rTHb}$ (8). In a neonatal swine model of HIE, HVx accurately identified the lower limit of autoregulation $(9,10)$. We sought to translate our laboratory work to neonates with HIE.

The goal of this pilot study was to describe the relationship between autoregulation and neurologic injury on magnetic resonance imaging (MRI) in neonates with HIE who receive therapeutic hypothermia. First, we determined whether HVx would identify $\mathrm{MAP}_{\mathrm{OPT}}$. Second, we investigated whether neonates who spent more time with blood pressure below $\mathrm{MAP}_{\text {OPT }}$ and who had greater blood pressure deviation below $\mathrm{MAP}_{\mathrm{OPT}}$ would have more severe neurologic injury than neonates whose blood pressure remained within or above $\mathrm{MAP}_{\mathrm{OPT}}$ Third, we assessed whether measurements based on HVx and

\footnotetext{
'Department of Pediatrics, Division of Neonatology, Johns Hopkins University School of Medicine (JHU), Baltimore, Maryland; ${ }^{2}$ Neurosciences Intensive Care Nursery Program, JHU, Baltimore, Maryland; ${ }^{3}$ Department of Radiology, Division of Pediatric Radiology, JHU, Baltimore, Maryland; ${ }^{4}$ Department of Pediatrics, Division of General Pediatrics and Adolescent Medicine, JHU, Baltimore, Maryland; ${ }^{5}$ Center for Child and Community Health Research, JHU, Baltimore, Maryland; ${ }^{6}$ Department of Anesthesiology and Critical Care Medicine, JHU, Baltimore, Maryland; ' Department of Anesthesiology, Texas Children's Hospital, Houston, Texas. Correspondence: Jennifer K. Lee (jklee@jhmi.edu) 
$\mathrm{MAP}_{\text {OPT }}$ would be more strongly associated with injury than regional cerebral oxygen saturation $\left(\mathrm{rSO}_{2}\right)$ or hemodynamic goals based on gestational age.

\section{RESULTS}

Forty-four neonates with HIE were identified. Seven families did not consent to enroll, and one family did not speak English or Spanish. Eight neonates were not eligible, including five who did not have arterial cannulae and three who died or had support withdrawn. Two neonates had intracranial hemorrhages or congenital heart disease, which precluded the use of hypothermia. Twenty-six neonates were enrolled in the study. Autoregulation monitoring could not be accomplished with one patient due to technical problems, and one neonate's MRI had motion artifact. Therefore, results were analyzed on 24 neonates ( 15 males and 9 females).

Of these 24 neonates, autoregulation monitoring was carried out during hypothermia in all patients, during rewarming in 22 patients, and during normothermia in 21 patients. Reasons for early cessation of monitoring included technical failure (one patient), early removal of the arterial cannula (one patient), and transfer to the pediatric ICU for extracorporeal membranous oxygenation (one patient).

\section{Patient Descriptions}

The mean gestational age was $39.2 \pm 1.5$ (SD) wk with birth weight $3,353 \pm 596 \mathrm{~g}$. Seventeen neonates $(71 \%)$ were born by cesarean section, and eight (33\%) required chest compressions after delivery. The umbilical cord gases had a mean $\mathrm{pH}$ of $6.98 \pm 0.13(n=19)$ and base deficit of $-13 \pm 3(n=17)$. Blood gases obtained within $1 \pm 0.5 \mathrm{~h}$ of birth had a mean $\mathrm{pH}$ of $7.11 \pm 0.17(n=24)$ and base deficit of $-18 \pm 6(n=21)$. Sixteen neonates $(67 \%)$ had moderate encephalopathy, and eight (33\%) had severe encephalopathy. Median Apgar scores were 2 (range: $0-7$ ), 4 (range: $0-8$ ), and 6 (range: $2-9$ ) at 1,5 , and $10 \mathrm{~min}$ of life. Fourteen patients $(58 \%)$ had seizures diagnosed clinically or electrographically, and all were treated with phenobarbital. Six neonates also received fosphenytoin, levetiracetam, or topiramate. Head ultrasounds were abnormal in 18 patients (75\%): all 18 had cerebral edema, 1 had a germinal matrix hemorrhage, and 1 had cystic white matter changes. None of the neonates had an intraventricular hemorrhage. Eight neonates (33\%) received opiate infusions; 16 (67\%) received vasoactive infusions, including dopamine (16/24), dobutamine (15/24), epinephrine (1/24), and milrinone (2/24); and $22(92 \%)$ had respiratory compromise. Eighteen neonates (75\%) were mechanically ventilated with a mean oxygenation index of $3.7 \pm 3$ at the beginning of the study. One neonate had a positive bacterial blood culture. The patients physiologic and laboratory variables are shown in Table 1. All enrolled neonates survived to Neonatal Intensive Care Unit discharge.

\section{Neurologic Injury}

Brain MRIs were obtained 3-7 d after treatment on $9 \pm 3$ days of life (range: 4-14 d). Three neonates had no injuries in any region. Twenty-one had injury in at least one region, and four had moderate/severe injury in all regions. Moderate/severe injury was more common in the white matter than that in paracentral gyri, basal ganglia, thalamus, or brainstem (Table 2). No infants had selective, unilateral brain injury.

\section{Blood Pressure and Autoregulation}

The median duration of $\mathrm{HVx}$ monitoring was $30.9 \mathrm{~h}$ (interquartile range (IQR): $22.6,42.6 ; n=24), 6.5 \mathrm{~h}$ (IQR: $5.4,7.9 ; n=22$ ), and $6 \mathrm{~h}$ (IQR: 6,$6 ; n=21$ ) during hypothermia, rewarming, and normothermia, respectively. Figure 1 illustrates the neonates' range of MAP. $\mathrm{MAP}_{\mathrm{OPT}}$ was identified in 19 of 24 (79\%), 17 of $22(77 \%)$, and 18 of 21 (86\%) neonates during hypothermia, rewarming, and normothermia. The median $\mathrm{MAP}_{\mathrm{OPT}}$ bin was $45 \mathrm{~mm} \mathrm{Hg}$ (IQR: 45,$55 ; n=19), 50 \mathrm{~mm} \mathrm{Hg}$ (IQR: 45, 50; $n=$ 17), and $50 \mathrm{~mm} \mathrm{Hg}$ (IQR: 45, 55; $n=18$ ) during hypothermia, rewarming, and normothermia. In some individual patients, the $\mathrm{MAP}_{\mathrm{OPT}}$ differed between time periods. Neonates with no or mild brain injuries had no or minimal change in $\mathrm{MAP}_{\mathrm{OPT}}$ as they progressed from hypothermia to rewarming in comparison with neonates with moderate/severe injuries (Figure 2).

Patients with moderate/severe injuries in paracentral gyri, white matter, basal ganglia, thalamus, and brainstem spent a greater proportion of time with blood pressure below $\mathrm{MAP}_{\mathrm{OPT}}$ during rewarming than uninjured neonates. Injury severity in paracentral gyri, white matter, basal ganglia, and thalamus correlated with the percentage of time spent below $\mathrm{MAP}_{\mathrm{OPT}}$ during rewarming. Neonates with no or mild injuries in all brain regions spent a greater proportion of time with blood pressure within the $\mathrm{MAP}_{\text {ОРт }}$ bin than patients with moderate/severe injuries (Figure 3 and Table 3).

During normothermia, neonates with injuries in white matter and brainstem spent a greater proportion of time with blood pressure below $\mathrm{MAP}_{\mathrm{OPT}}$ than neonates without injuries in these regions. Injury severity in the white matter increased with more time below $\mathrm{MAP}_{\mathrm{OPT}}$. Neonates with no or mild injuries in all regions spent a greater proportion of time with blood pressure above $\mathrm{MAP}_{\text {ОРт }}$ than neonates with moderate/severe

Table 1. Physiologic variables and laboratory measurements during the study period $(n=24)$

\begin{tabular}{lccc}
\hline Parameter & Hypothermia & Rewarming & Normothermia \\
\hline Temperature $\left({ }^{\circ} \mathrm{C}\right)$ & $33.5(0.3)$ & $35.2(0.4)$ & $36.9(0.3)$ \\
Heart rate $(\mathrm{bpm})$ & $108(12)$ & $117(13)$ & $135(17)$ \\
$\mathrm{MAP}(\mathrm{mm} \mathrm{Hg})$ & $52(5)$ & $49(4)$ & $50(4)$ \\
$\mathrm{pH}$ & $7.37(0.04)$ & $7.37(0.06)$ & $7.37(0.05)$ \\
$\mathrm{Paco}_{2}(\mathrm{~mm} \mathrm{Hg})$ & $43(6)$ & $48(9)$ & $48(7)$ \\
$\mathrm{PaO}_{2}(\mathrm{~mm} \mathrm{Hg})$ & $115(47)$ & $94(29)$ & $105(48)$ \\
$\mathrm{Hemoglobin}(\mathrm{g} / \mathrm{dl})$ & $15.2(1.2)$ & $13.7(0.7)^{\mathrm{a}}$ & $13.4(0.6)^{\mathrm{b}}$ \\
$\mathrm{WBC}(\mathrm{no} . \mathrm{of}$ & $10,032(3,156)$ & $8,315(3,646)^{\mathrm{a}}$ & $9,566(1,423)^{\mathrm{b}}$ \\
${\left.\text { Cells } / \mathrm{mm}^{3}\right)}$ & & $138(3)^{\mathrm{a}}$ & $141(3)^{\mathrm{b}}$ \\
Sodium $(\mathrm{mEq} / \mathrm{l})$ & $138(3)$ & & \\
\hline
\end{tabular}

Data are shown as means with SD.

bpm, beats per minute; MAP, mean arterial blood pressure; WBC, white blood cell count.

aLaboratory measurements were taken in nine patients. 'Laboratory measurements were taken in 11 patients. 
injuries. Injuries in the paracentral gyri, white matter, basal ganglia, and thalamus were less severe in neonates who spent more time above $\mathrm{MAP}_{\mathrm{OPT}}$ (Figure 4 and Table 4 ).

Neurologic injury and the percentages of time spent with blood pressure below, within, or above $\mathrm{MAP}_{\mathrm{OPT}}$ were not consistently associated during hypothermia (Table 5). Furthermore, time spent below the MAP threshold of gestational age +5 did not correlate with injury severity in any brain region (Table 6). Patients spent little time with MAP below their gestational age (data not shown).

Brain injury was also associated with maximal deviation in blood pressure from $\mathrm{MAP}_{\mathrm{OPT}}$ during rewarming. Neonates with no, mild, or moderate/severe injury in paracentral gyri had median MAP deviations below $\mathrm{MAP}_{\mathrm{OPT}}$ of $10 \mathrm{~mm} \mathrm{Hg}$ (IQR: 5, 10), $15 \mathrm{~mm} \mathrm{Hg}$ (IQR: 15, 20), and $15 \mathrm{~mm} \mathrm{Hg}$ (IQR: $5,15)$, respectively. For neonates with no, mild, or moderate/ severe injury in basal ganglia, the median MAP deviations below $\mathrm{MAP}_{\text {OPT }}$ were $10 \mathrm{~mm} \mathrm{Hg}$ (IQR: 5, 15), $12.5 \mathrm{~mm} \mathrm{Hg}$ (IQR: 10, 15), and $15 \mathrm{~mm} \mathrm{Hg}$ (IQR: 5, 15). Patients with no, mild, or moderate/severe injury in thalamus had median MAP deviations below $\mathrm{MAP}_{\text {OPT }}$ of $10 \mathrm{~mm} \mathrm{Hg}$ (IQR: 5,15$), 10 \mathrm{~mm} \mathrm{Hg}$ (IQR: 10, 15), and $15 \mathrm{~mm} \mathrm{Hg}$ (IQR: 5, 15).

Neonates with no or mild injury in all brain regions had greater blood pressure deviation above $\mathrm{MAP}_{\mathrm{OPT}}$ during rewarming than patients with moderate/severe injury. During normothermia, neonates with no or mild injury in paracentral

Table 2. Summary of anatomical and diffusion MRI findings

\begin{tabular}{|c|c|}
\hline Brain region & $\begin{array}{c}\text { Number of } \\
\text { patients }\end{array}$ \\
\hline \multicolumn{2}{|l|}{ Paracentral gyri } \\
\hline No injury & 14 \\
\hline Mild injury & 4 \\
\hline Moderate/severe injury & 6 \\
\hline \multicolumn{2}{|l|}{ White matter ${ }^{\mathrm{a}}$} \\
\hline No injury & 5 \\
\hline Mild injury & 7 \\
\hline Moderate/severe injury & 12 \\
\hline \multicolumn{2}{|l|}{ Basal ganglia } \\
\hline No injury & 11 \\
\hline Mild injury & 7 \\
\hline Moderate/severe injury & 6 \\
\hline \multicolumn{2}{|l|}{ Thalamus } \\
\hline No injury & 10 \\
\hline Mild injury & 8 \\
\hline Moderate/severe injury & 6 \\
\hline \multicolumn{2}{|l|}{ Brainstem } \\
\hline No injury & 12 \\
\hline Mild injury & 7 \\
\hline Moderate/severe injury & 5 \\
\hline
\end{tabular}

gyri, white matter, basal ganglia, and thalamus also had greater blood pressure deviation above $\mathrm{MAP}_{\mathrm{OPT}}$ than patients with moderate/severe injury (data not shown). No complications were associated with the autoregulation monitoring.

Among neonates with an identified $\mathrm{MAP}_{\mathrm{OPT}}$ during hypothermia, rewarming, and normothermia, the rates of moderate/ severe injury in paracentral gyri, basal ganglia, thalamus, and brainstem were similar or greater than the rates of moderate/ severe injury in these regions in neonates without an identified $\mathrm{MAP}_{\mathrm{OPT}}$ The proportions of neonates with moderate/severe white matter injury were similar between those with and without an identified $\mathrm{MAP}_{\text {OPT }}$ during rewarming (data not shown). Of the neonates with an $\mathrm{MAP}_{\mathrm{OPT}}$ during hypothermia $(n=19)$, $74 \%$ had moderate/severe white matter injury, whereas $100 \%$ of neonates without an $\mathrm{MAP}_{\text {OPT }}$ during hypothermia $(n=5)$ had moderate/severe white matter injury. During normother$\mathrm{mia}$, the rate of moderate/severe white matter injury was $83 \%$
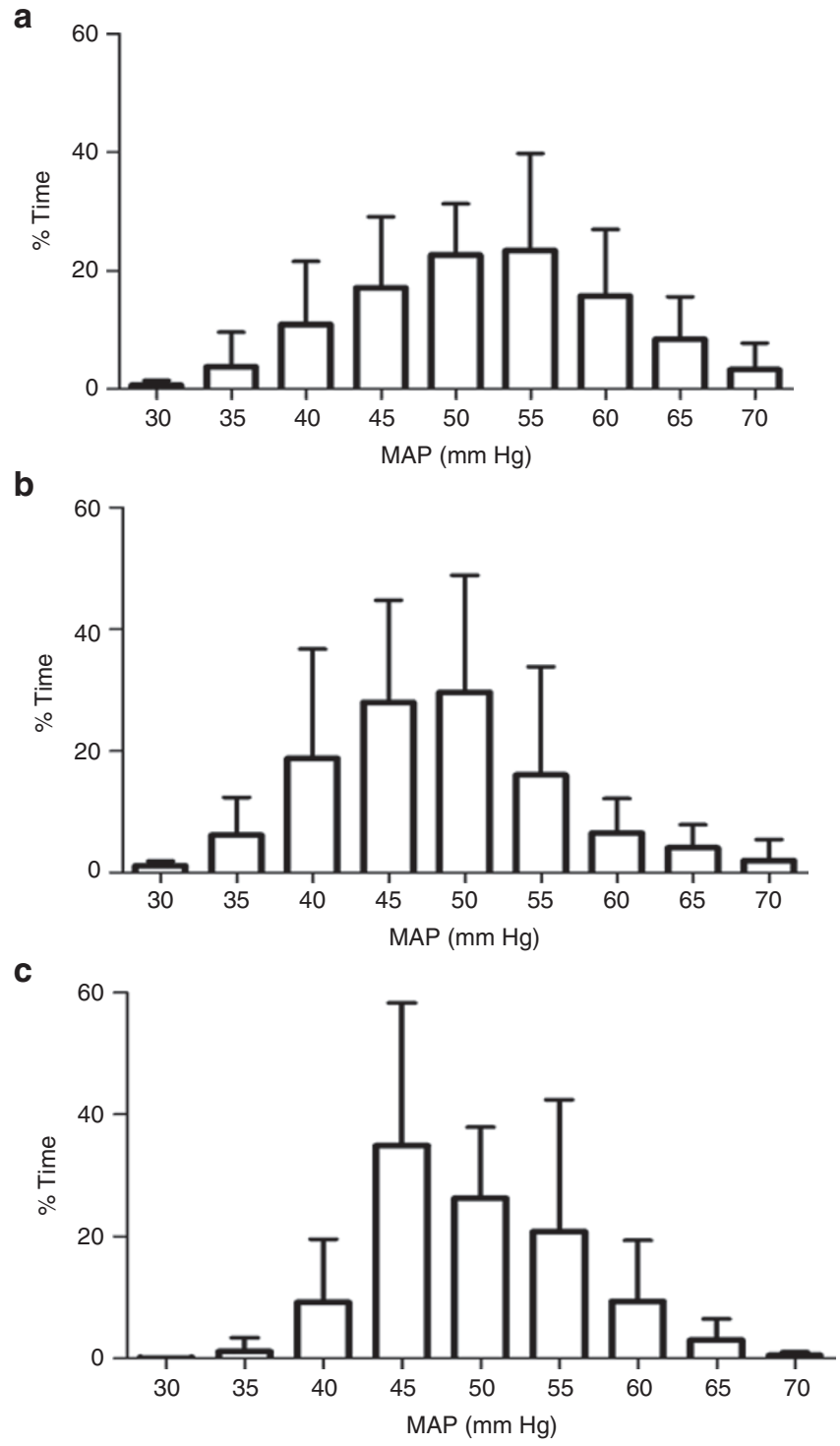

Figure 1. The percentage of time during (a) hypothermia $(n=24)$, (b) rewarming $(n=22)$, and (c) normothermia $(n=21)$ that neonates spent at each mean arterial blood pressure. Data are shown as means with SD. 


\section{Articles | Howlett et al.}

a

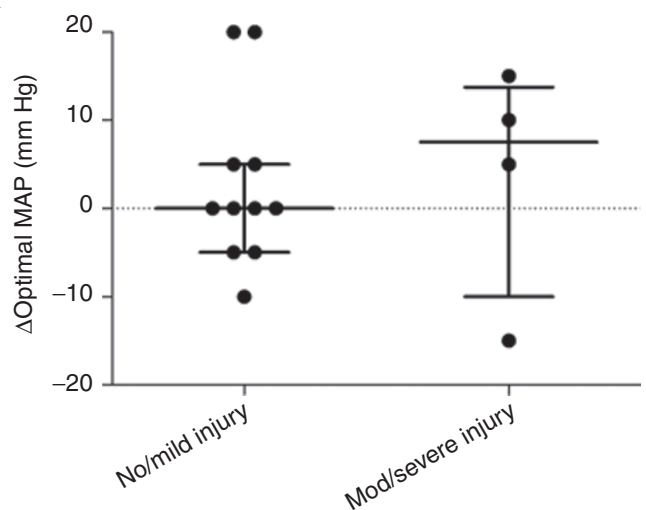

b

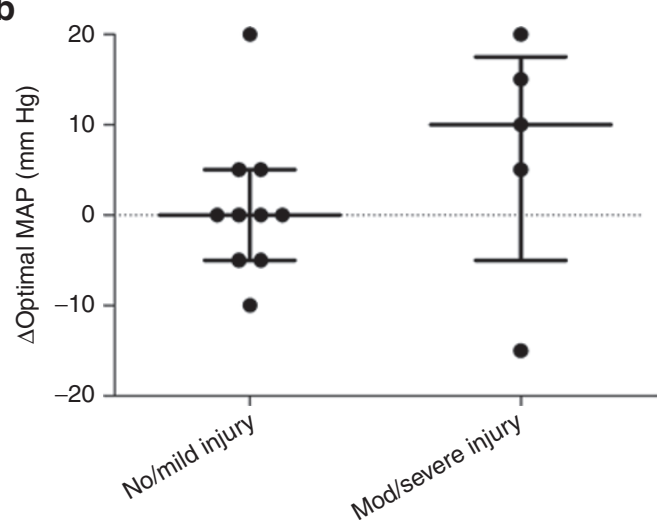

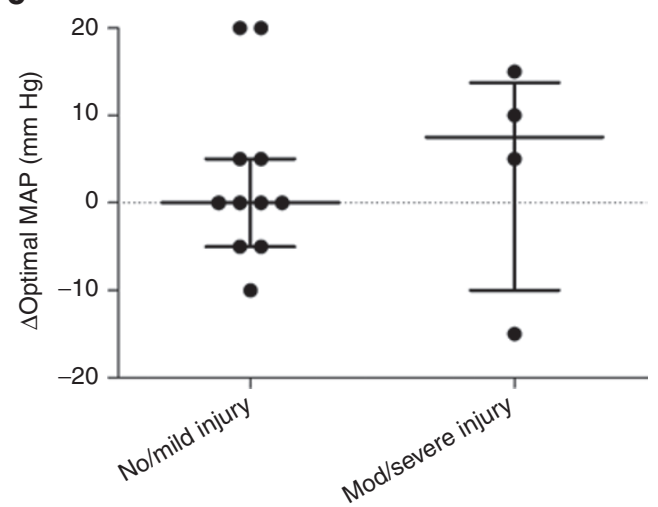

d

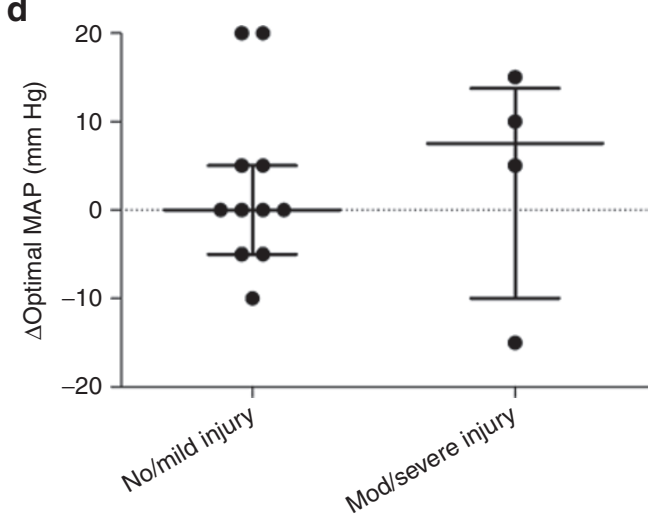

Figure 2. Fifteen neonates had an identifiable optimal mean arterial blood pressure $\left(M^{\prime} P_{O P T}\right)$ during both hypothermia and rewarming. When progressing from hypothermia to rewarming, some individuals had a shift in MAP . This shift is represented on the $y$-axis. For instance, a value of 5 indicates that the $\mathrm{MAP}_{\mathrm{OPT}}$ increased by $5 \mathrm{~mm} \mathrm{Hg}$ as the patient moved from hypothermia to rewarming. A value of 0 represents no shift. Patients with no or mild injury in (a) paracentral gyri, (b) white matter, (c) basal ganglia, and (d) thalamus had no or minimal shift in MAP ${ }_{\text {oPT }}$ when moving from hypothermia to rewarming. Data are shown as medians and interquartile ranges. Each circle represents one neonate.

in neonates with an $\mathrm{MAP}_{\mathrm{OPT}}(n=18)$ and $100 \%$ in neonates without an $\operatorname{MAP}_{\mathrm{OPT}}(n=3)$.

\section{Cerebral Oximetry}

Patients with moderate/severe injuries had slightly higher $\mathrm{rSO}_{2}$ values than patients with no or mild injuries (Table 7). Phenobarbital was administered to 14 neonates during hypothermia, 2 neonates during rewarming, and 5 neonates during normothermia. As compared with those with no or mild injuries, a higher proportion of neonates with moderate/ severe injuries received phenobarbital during hypothermia or rewarming and received a second antiepileptic (fosphenytoin, levetiracetam, or topiramate) during hypothermia, rewarming, or normothermia. Neonates with moderate/severe injuries had median $\mathrm{PaO}_{2}$ values of 82-122 $\mathrm{mm} \mathrm{Hg}$, and those with no or mild injuries had $\mathrm{PaO}_{2}$ levels of 39-155 mm Hg during hypothermia, rewarming, and normothermia. $\mathrm{PaCO}_{2}$, arterial oxygen saturation, hemoglobin levels, the administration of opiate infusions, and the incidence of red blood cell transfusions were not associated with injury or $\mathrm{rSO}_{2}$ (data not shown).

\section{DISCUSSION}

The results of this pilot study suggest that continuous autoregulation monitoring with $\mathrm{HVx}$ may identify blood pressures associated with reduced risk of neurologic injury in neonatal HIE. HVx successfully identified $\mathrm{MAP}_{\mathrm{OPT}}$ during therapeutic hypothermia, rewarming, and normothermia. Descriptive analyses identified an association between neurologic injury and blood pressure in relation to $\mathrm{MAP}_{\mathrm{OPT}}$. By contrast, MAP goals based on the gestational age +5 were not associated with brain injury. Greater severity of brain injury in neonates was associated with more time spent with blood pressure below $\mathrm{MAP}_{\mathrm{OPT}}$ during rewarming. Conversely, neonates with no or mild injury spent more time with blood pressure within or above MAP ${ }_{\text {OPT }}$. Moreover, patients with no injury or only mild injury had minimal shift in $\mathrm{MAP}_{\mathrm{OPT}}$ when moving from hypothermia to rewarming.

Because this was an observational study, we do not know if maintaining MAP within or above $\mathrm{MAP}_{\mathrm{OPT}}$ provides neuroprotection or is the result of better cardiovascular regulation in those with less injury. However, the data suggest that maintaining blood pressure within or above $\mathrm{MAP}_{\mathrm{OPT}}$ may be safer than maintaining blood pressure below $\mathrm{MAP}_{\mathrm{OPT}}$. Clinicians use many techniques to maintain cerebral perfusion, including selecting a minimal tolerable MAP of gestational age +5 or monitoring $\mathrm{rSO}_{2}$. Thresholds of MAP based on gestational age did not correlate with neurologic injury in this study. Absolute $\mathrm{rSO}_{2}$ values depend on cerebral metabolic rate, which varies with 
a

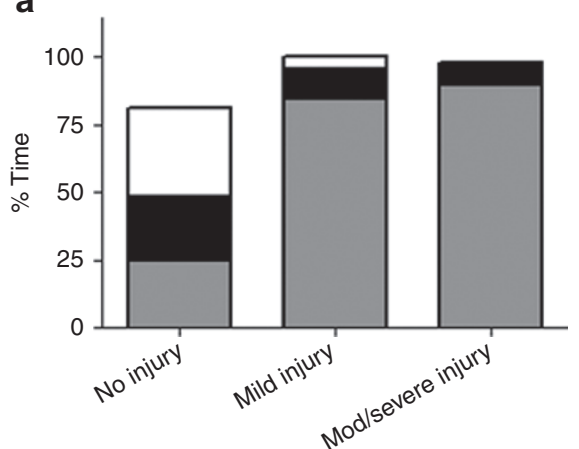

d

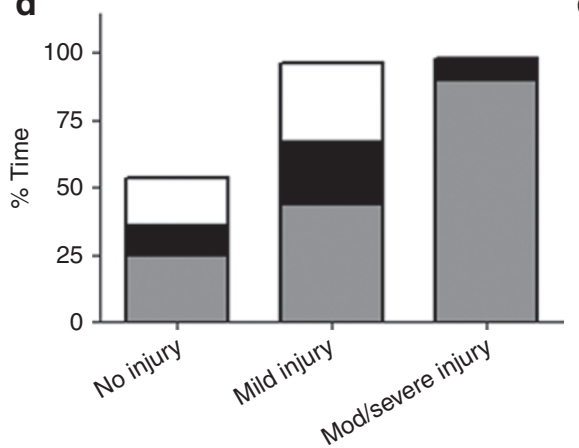

b

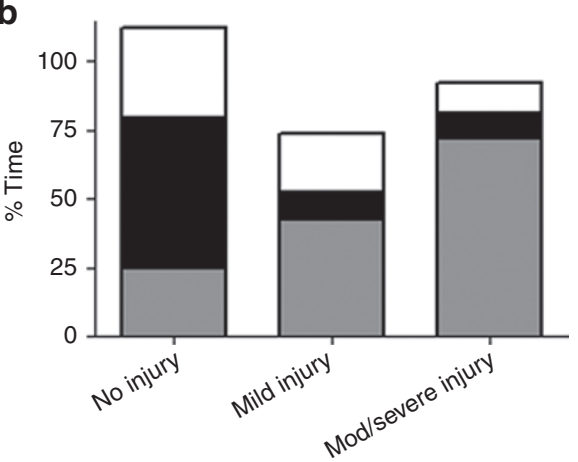

e

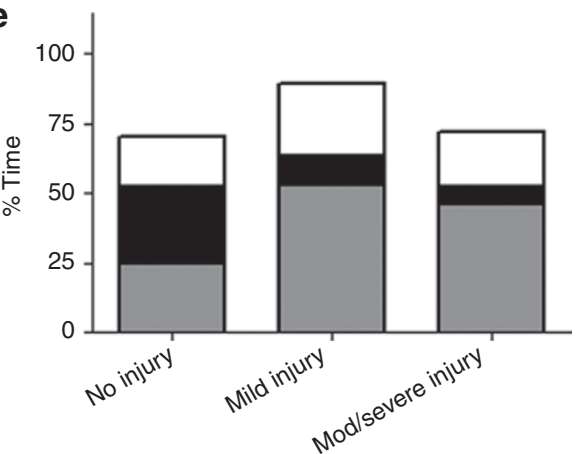

C

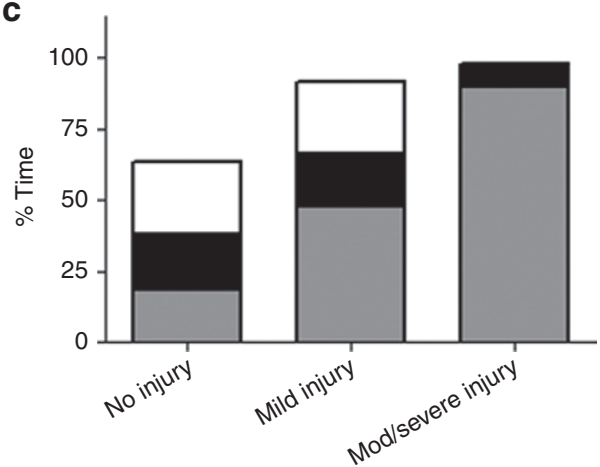

Figure 3. The percentage of time that neonates $(n=17)$ spent below, within, or above the optimal mean arterial blood pressure bin $\left(\mathrm{MAP}_{\mathrm{OPT}}\right)$ during rewarming in relation to injury in (a) paracentral gyri, (b) white matter, (c) basal ganglia, (d) thalamus, and (e) brainstem. Gray represents the percentage of time spent with blood pressure below $\mathrm{MAP}_{\mathrm{OPT}}$. Black represents the percentage of time spent with blood pressure within MAP ${ }_{\text {OPT }}$. White represents the percentage of time spent with blood pressure above $\mathrm{MAP}_{\mathrm{OPT}}$ Neonates with injuries in all regions spent more time with blood pressure below $\mathrm{MAP}_{\mathrm{OPT}}$ than patients without injury. The degree of injury in paracentral gyri, white matter, basal ganglia, and thalamus increased with greater time below $\mathrm{MAP}_{\mathrm{OPT}}$ Neonates with no or mild injury spent a greater proportion of time with blood pressure within the MAP ${ }_{\text {OPT }}$ bin than patients with moderate/severe injury. Data are displayed as medians.

Table 3. Brain injury and percent of time spent in relation to optimal MAP during rewarming

\begin{tabular}{|c|c|c|c|}
\hline Brain region & $\begin{array}{c}\text { Below optimal MAP } \\
(\% \text {, median, IQR) }\end{array}$ & $\begin{array}{l}\text { At optimal MAP } \\
(\%, \text { median, IQR) }\end{array}$ & $\begin{array}{l}\text { Above optimal MAP } \\
(\%, \text { median, IQR) }\end{array}$ \\
\hline \multicolumn{4}{|l|}{ Paracentral gyri } \\
\hline No injury & $25(9,52)$ & $24(5,28)$ & $33(22,63)$ \\
\hline Mild injury & $85(41,89)$ & $11(9,44)$ & $4(2,14)$ \\
\hline Moderate/severe injury & $90(2,92)$ & $8(2,10)$ & $0(0,39)$ \\
\hline \multicolumn{4}{|l|}{ White matter } \\
\hline Mild injury & $42(5,84)$ & $10(3,27)$ & $22(8,80)$ \\
\hline Moderate/severe injury & $72(2,92)$ & $9(2,24)$ & $11(0,39)$ \\
\hline \multicolumn{4}{|l|}{ Basal ganglia } \\
\hline No injury & $19(9,85)$ & $19(9,54)$ & $25(4,63)$ \\
\hline Mild injury & $48(41,54)$ & $18(5,26)$ & $26(14,35)$ \\
\hline Mild injury & $44(9,44)$ & $24(5,24)$ & $29(14,29)$ \\
\hline Moderate/severe injury & $90(2,90)$ & $8(2,8)$ & $0(0,0)$ \\
\hline \multicolumn{4}{|l|}{ Brainstem } \\
\hline No injury & $25(9,85)$ & $28(9,54)$ & $18(4,63)$ \\
\hline Mild injury & $53(44,84)$ & $11(5,24)$ & $26(12,35)$ \\
\hline Moderate/severe injury & $46(1,94)$ & $6(2,34)$ & $20(0,69)$ \\
\hline
\end{tabular}

IQR, interquartile range; MAP, mean arterial blood pressure. 


\section{Articles | Howlett et al.}
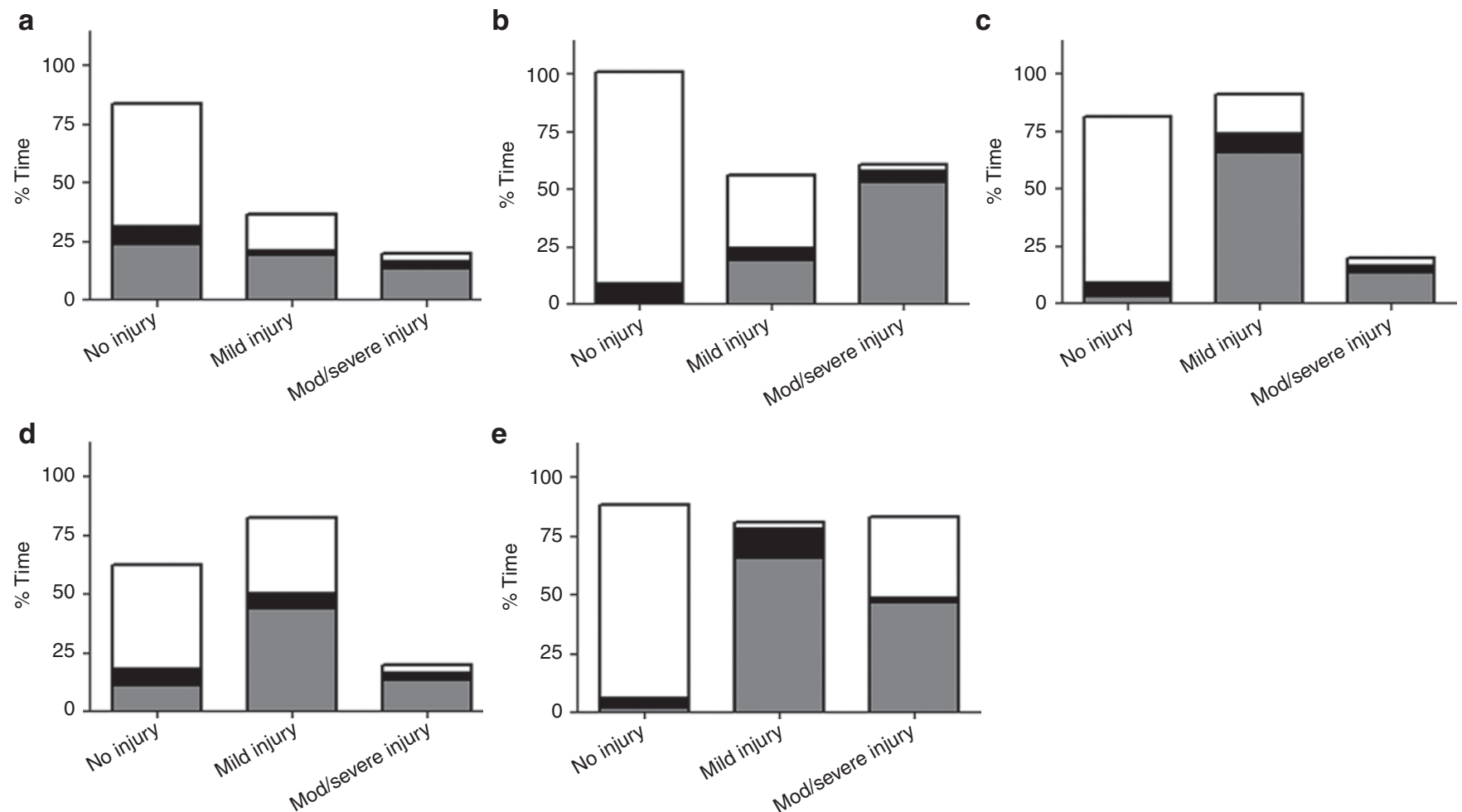

Figure 4. The percentage of time neonates $(n=18)$ spent below, within, or above the optimal mean arterial blood pressure bin (MAP $\left.{ }_{\mathrm{OPT}}\right)$ during normothermia in relation to injury in (a) paracentral gyri, (b) white matter, (c) basal ganglia, (d) thalamus, and (e) brainstem. Gray represents the percentage of time spent with blood pressure below MAP ${ }_{O P T}$. Black represents the percentage of time spent with blood pressure within MAP ${ }_{O P T}$. White represents the percentage of time spent with blood pressure above $\mathrm{MAP}_{\mathrm{OPT}}$. Patients with injury in white matter and brainstem, and patients with more severe injury in white matter spent more time with blood pressure below MAP ${ }_{\mathrm{OPT}}$. Neonates with no or mild injury in all regions spent more time with blood pressure above $\mathrm{MAP}_{\mathrm{OPT}}$ than patients with moderate/severe injury. Injury severity was lower in paracentral gyri, white matter, basal ganglia, and thalamus with greater time spent above MAP ${ }_{\mathrm{OPT}}$. Data are displayed as medians.

temperature, sedation, antiepileptic treatment, oxygen saturation, and hematocrit. Because these variables change frequently in neonates with $\mathrm{HIE}$, interpretation of $\mathrm{rSO}_{2}$ is challenging and is unlikely to define optimal cerebral perfusion pressure as a single measure. Alternatively, $\mathrm{HVx}$ is calculated from MAP and rTHb, a surrogate measure of CBV (8). HVx is less affected by cerebral oxygenation and primarily reflects changes in cerebral vasoconstriction/vasodilation during autoregulatory responses to changing perfusion pressure. We theorized that identifying $\mathrm{MAP}_{\mathrm{OPT}}$ with $\mathrm{HVx}$ would be a more reliable method of guiding hemodynamic management to support cerebral perfusion. Indeed, neonates who had no neurologic injury or only mild injury spent more time with blood pressures within or above $\mathrm{MAP}_{\mathrm{OPT}}$ than neonates with moderate/severe injuries.

The association between time spent within $\mathrm{MAP}_{\mathrm{OPT}}$ and less neurologic injury was strongest during the rewarming period for the paracentral gyri and white matter. NIRS measures superficial cortex, and cortical measurements of rTHb would most closely reflect vasoreactivity in the paracentral gyri. The white matter, posterior limb of the internal capsule, basal ganglia, thalamus, and brainstem are also vulnerable to hypoxic injury. In neonatal HIE, early MRI evidence of basal ganglia and thalamic injury are associated with future motor impairments, and brainstem injury is associated with death (11). The association between basal ganglia and thalamic injury and
$\mathrm{MAP}_{\text {OPT }}$ suggests that cortical autoregulation measurements reflect vascoreactivity in deeper regions and that $\mathrm{MAP}_{\mathrm{OPT}}$ may be similar in all brain regions. Alternatively, injury to deep brain structures may cause cardiovascular instability and poor autoregulatory function measured in the cortex. Because brainstem injury may induce hemodynamic instability and impaired autoregulation could cause brainstem injury, we expected a complex association between autoregulation and brainstem injury.

Related findings have been reported in adults. In adults with traumatic brain injury, mortality increased as cerebral perfusion pressure (CPP) decreased below optimal $\mathrm{CPP}\left(\mathrm{CPP}_{\mathrm{OPT}}\right)$ (4). Spending more time with CPP below $\mathrm{CPP}_{\mathrm{OPT}}$ was associated with severe disability, vegetative state, or death in adults with aneurysmal subarachnoid hemorrhage (12). Neonates with no or mild injury had greater maximal blood pressure deviation above $\mathrm{MAP}_{\mathrm{OPT}}$ than those with moderate/severe injury in our study. By contrast, a greater difference in median CPP above $\mathrm{CPP}_{\mathrm{OPT}}$ was associated with severe disability in adult traumatic brain injury (4). We evaluated the maximal deviation in MAP above $\mathrm{MAP}_{\mathrm{OPT}}$, and neonates spent little time at higher blood pressures (Figure 1). Additional studies are needed to evaluate the effects of higher blood pressures in HIE.

In several patients, the $\mathrm{MAP}_{\mathrm{OPT}}$ value changed between the hypothermic and rewarming periods. Neonates with no or 
Table 4. Brain injury and percent of time spent in relation to optimal MAP during normothermia

\begin{tabular}{|c|c|c|c|}
\hline Brain region & $\begin{array}{l}\text { Below optimal } \\
\text { MAP } \\
\text { (\%, median, IQR) }\end{array}$ & $\begin{array}{c}\text { At optimal } \\
\text { MAP } \\
(\%, \text { median, IQR) }\end{array}$ & $\begin{array}{c}\text { Above optimal } \\
\text { MAP } \\
(\% \text {, median, IQR) }\end{array}$ \\
\hline \multicolumn{4}{|l|}{ Paracentral gyri } \\
\hline No injury & $24(0,93)$ & $8(3,14)$ & $52(1,92)$ \\
\hline Mild injury & $19(1,99)$ & $2(1,65)$ & $16(0,98)$ \\
\hline $\begin{array}{l}\text { Moderate/ } \\
\text { severe injury }\end{array}$ & $13(0,93)$ & $3(2,33)$ & $4(2,67)$ \\
\hline \multicolumn{4}{|l|}{ White matter } \\
\hline No injury & $1(0,87)$ & $8(3,10)$ & $92(3,97)$ \\
\hline Mild injury & $19(2,94)$ & $5(2,23)$ & $32(1,84)$ \\
\hline $\begin{array}{l}\text { Moderate/ } \\
\text { severe injury }\end{array}$ & $53(0,93)$ & $5(2,33)$ & $2(2,67)$ \\
\hline \multicolumn{4}{|l|}{ Basal ganglia } \\
\hline No injury & $3(0,94)$ & $5(2,24)$ & $73(0,97)$ \\
\hline Mild injury & $66(2,93)$ & $8(2,14)$ & $17(1,84)$ \\
\hline $\begin{array}{l}\text { Moderate/ } \\
\text { severe injury }\end{array}$ & $13(0,93)$ & $3(2,33)$ & $4(2,67)$ \\
\hline \multicolumn{4}{|l|}{ Thalamus } \\
\hline No injury & $11(1,94)$ & $7(3,24)$ & $44(0,92)$ \\
\hline Mild injury & $44(1,93)$ & $7(2,14)$ & $32(1,98)$ \\
\hline $\begin{array}{l}\text { Moderate/ } \\
\text { severe injury }\end{array}$ & $13(0,93)$ & $3(2,33)$ & $4(2,67)$ \\
\hline \multicolumn{4}{|l|}{ Brainstem } \\
\hline No injury & $2(0,57)$ & $4(2,16)$ & $82(8,97)$ \\
\hline Mild injury & $66(13,93)$ & $12(7,23)$ & $3(1,32)$ \\
\hline $\begin{array}{l}\text { Moderate/ } \\
\text { severe injury }\end{array}$ & $47(0,95)$ & $2(2,18)$ & $34(2,82)$ \\
\hline
\end{tabular}

IQR, interquartile range; MAP, mean arterial blood pressure.

mild injury had no or minimal change in $\mathrm{MAP}_{\mathrm{OPT}}$. The lower limit of autoregulation shifts to a higher CPP with intracranial hypertension (5). Theoretically, if intracranial pressure increased during rewarming in the more severely injured patients (13), a shift in the autoregulation curve could also shift $\mathrm{MAP}_{\mathrm{OPT}}$ Variation in $\mathrm{MAP}_{\mathrm{OPT}}$ among patients and changes in $\mathrm{MAP}_{\mathrm{OPT}}$ within patients emphasize the importance of using continuous, real-time autoregulation monitoring to individualize hemodynamic goals.

We did not identify a correlation between neurologic injury and $\mathrm{MAP}_{\mathrm{OPT}}$ during hypothermia. Hypothermia may preserve the cerebral vasodilatory response to hypotension. In a swine model of neonatal HIE, hypothermia acutely decreased the lower limit of autoregulation (9). If the lower limit of autoregulation was decreased during hypothermia in our patients, the adverse effect of blood pressure below $\mathrm{MAP}_{\mathrm{OPT}}$ would be diminished.

Neonates with moderate/severe neurologic injuries had slightly higher $\mathrm{rSO}_{2}$. As compared with their counterparts, these patients more often received phenobarbital, which suppresses cerebral metabolism and increases $\mathrm{rSO}_{2}$. Whether more severe neurologic injury is consistently associated with
Table 5. Brain injury and percent of time spent in relation to optimal MAP during hypothermia

\begin{tabular}{|c|c|c|c|}
\hline Brain region & $\begin{array}{l}\text { Below optimal } \\
\text { MAP } \\
\text { (\%, median, IQR) }\end{array}$ & $\begin{array}{c}\text { At optimal } \\
\text { MAP } \\
(\%, \text { median, IQR) }\end{array}$ & $\begin{array}{c}\text { Above optimal } \\
\text { MAP } \\
\text { (\%, median, IQR) }\end{array}$ \\
\hline \multicolumn{4}{|l|}{ Paracentral gyri } \\
\hline No injury & $11(1,43)$ & $12(6,19)$ & $78(26,90)$ \\
\hline Mild injury & $47(0,96)$ & $2(1,3)$ & $50(1,99)$ \\
\hline $\begin{array}{l}\text { Moderate/ } \\
\text { severe injury }\end{array}$ & $1(0,16)$ & $27(3,27)$ & $73(57,96)$ \\
\hline \multicolumn{4}{|l|}{ White matter } \\
\hline No injury & $55(1,64)$ & $12(11,19)$ & $26(13,87)$ \\
\hline Mild injury & $5(0,41)$ & $4(2,12)$ & $90(46,98)$ \\
\hline $\begin{array}{l}\text { Moderate/ } \\
\text { severe injury }\end{array}$ & $1(0,16)$ & $27(3,27)$ & $73(57,96)$ \\
\hline \multicolumn{4}{|l|}{ Basal ganglia } \\
\hline No injury & $5(1,55)$ & $6(2,12)$ & $87(26,90)$ \\
\hline Mild injury & $41(0,43)$ & $14(3,24)$ & $7(21,97)$ \\
\hline $\begin{array}{l}\text { Moderate/ } \\
\text { severe injury }\end{array}$ & $1(0,16)$ & $27(3,27)$ & $73(57,96)$ \\
\hline \multicolumn{4}{|l|}{ Thalamus } \\
\hline No injury & $11(1,75)$ & $8(3,12)$ & $78(14,89)$ \\
\hline Mild injury & $20(0,43)$ & $8(2,24)$ & $71(21,98)$ \\
\hline $\begin{array}{l}\text { Moderate/ } \\
\text { severe injury }\end{array}$ & $1(0,16)$ & $27(3,27)$ & $73(57,96)$ \\
\hline \multicolumn{4}{|l|}{ Brainstem } \\
\hline No injury & $3(0,55)$ & $5(2,12)$ & $88(26,98)$ \\
\hline Mild injury & $41(22,43)$ & $24(14,35)$ & $44(21,46)$ \\
\hline $\begin{array}{l}\text { Moderate/ } \\
\text { severe injury }\end{array}$ & $1(0,8)$ & $15(3,27)$ & $84(65,97)$ \\
\hline
\end{tabular}

higher $\mathrm{rSO}_{2}$ requires additional studies. Nonetheless, in situations with frequent changes in cerebral metabolism, we propose that autoregulation monitoring with $\mathrm{HVx}$ would be better than $\mathrm{rSO}_{2}$ alone to guide hemodynamic management. Additional studies are needed to evaluate this theory.

Metabolic acidosis (14), prostaglandins (15), and altered adenosine homeostasis $(16,17)$ after hypoxia may affect CBF regulation (17-19). Autoregulation monitoring was initiated once study consent was obtained and after an arterial cannula was placed. It is possible that before monitoring was established, some neonates may have had severe metabolic derangements with altered autoregulatory function. Moreover, rewarming may increase lactate, adenosine, and prostaglandin production in injured regions of brain and limit myogenic reactivity and the range of autoregulation. Because the brain was not imaged early after rewarming, the timing of the injury and alterations in vasoreactivity cannot be linked on an individual basis.

An association between impaired autoregulation and mortality in neonatal HIE has been suggested previously. Using Xenon techniques 2-3 times over a 2-h period in neonates with asphyxia, Pryds et al. (20) reported an association between pressure-passive CBF and death. Our findings expand 
Table 6. Brain injury and percentage of time spent with mean arterial blood pressure below the gestational age +5

\begin{tabular}{|c|c|c|c|}
\hline Brain region & $\begin{array}{l}\text { Hypothermia (\%, } \\
\text { median, IQR) }\end{array}$ & $\begin{array}{c}\text { Rewarming } \\
(\%, \text { median, IQR) }\end{array}$ & $\begin{array}{l}\text { Normothermia } \\
(\% \text {, median, IQR) }\end{array}$ \\
\hline \multicolumn{4}{|l|}{ Paracentral gyri } \\
\hline No injury & $14(3,20)$ & $25(9,44)$ & $3(0,31)$ \\
\hline Mild injury & $17(8,32)$ & $53(3,62)$ & $19(2,31)$ \\
\hline $\begin{array}{l}\text { Moderate/ } \\
\text { severe injury }\end{array}$ & $15(3,22)$ & $5(2,21)$ & $5(2,33)$ \\
\hline \multicolumn{4}{|l|}{ White matter } \\
\hline No injury & $11(8,13)$ & $21(15,34)$ & $3(0,39)$ \\
\hline Mild injury & $16(3,20)$ & $39(2,53)$ & $2(0,31)$ \\
\hline $\begin{array}{l}\text { Moderate/ } \\
\text { severe injury }\end{array}$ & $16(3,28)$ & $8(2,53)$ & $5(2,33)$ \\
\hline \multicolumn{4}{|l|}{ Basal ganglia } \\
\hline No injury & $13(2,20)$ & $25(9,44)$ & $3(0,25)$ \\
\hline Mild injury & $16(3,25)$ & $39(3,54)$ & $16(1,60)$ \\
\hline $\begin{array}{l}\text { Moderate/ } \\
\text { severe injury }\end{array}$ & $15(3,22)$ & $5(2,21)$ & $5(2,33)$ \\
\hline \multicolumn{4}{|l|}{ Thalamus } \\
\hline No injury & $16(5,20)$ & $33(6,48)$ & $3(0,31)$ \\
\hline Mild injury & $12(3,20)$ & $28(6,49)$ & $9(2,41)$ \\
\hline $\begin{array}{l}\text { Moderate/ } \\
\text { severe injury }\end{array}$ & $15(3,22)$ & $5(2,21)$ & $5(2,33)$ \\
\hline \multicolumn{4}{|l|}{ Brainstem } \\
\hline No injury & $12(2,20)$ & $19(3,44)$ & $2(0,19)$ \\
\hline Mild injury & $16(8,25)$ & $44(17,54)$ & $22(1,62)$ \\
\hline $\begin{array}{l}\text { Moderate/ } \\
\text { severe injury }\end{array}$ & $14(3,16)$ & $3(2,8)$ & $4(2,5)$ \\
\hline
\end{tabular}

IQR, interquartile range.

upon the relationship between autoregulation and neurologic outcomes. We obtained autoregulation measurements continuously over days and across a wide hemodynamic range. In individual patients, $\mathrm{HVx}$ identified $\mathrm{MAP}_{\mathrm{OPT}}$ and distinguished this MAP from levels with poorer autoregulation. Neonates with moderate/severe brain injury displayed an increase in $\mathrm{MAP}_{\mathrm{OPT}}$ when transitioning from hypothermia to rewarming despite similar blood pressure distributions between these periods, which suggests a rightward shift in the autoregulation curve. Deviation in blood pressure below $\mathrm{MAP}_{\mathrm{OPT}}$ was associated with worse neurologic injury. Therefore, we suggest that neonates with HIE and poor neurologic outcomes do not have completely impaired autoregulation. Rather, the blood pressure range within the confines of autoregulation may shift, necessitating an adjustment in hemodynamic management to maintain pressure-reactive CBF. This possibility emphasizes the importance of continuous autoregulation monitoring to individualize hemodynamic goals as injury evolves and therapeutic conditions change.

Our pilot study had limitations. First, monitoring duration differed among patients during hypothermia because monitoring was started after obtaining consent. The durations of
Table 7. Brain injury and absolute regional cerebral oxygen saturation (right and left averaged)

\begin{tabular}{|c|c|c|c|}
\hline Brain region & $\begin{array}{c}\text { Hypothermia } \\
(\% \text {, median, IQR) }\end{array}$ & $\begin{array}{c}\text { Rewarming (\%, } \\
\text { median, IQR) }\end{array}$ & $\begin{array}{l}\text { Normothermia } \\
(\% \text {, median, IQR) }\end{array}$ \\
\hline \multicolumn{4}{|l|}{ Paracentral gyri } \\
\hline No injury & $83(78,86)$ & $80(79,90)$ & $83(71,89)$ \\
\hline Mild injury & $90(85,92)$ & $90(78,94)$ & $89(78,91)$ \\
\hline $\begin{array}{l}\text { Moderate/ } \\
\text { severe injury }\end{array}$ & $90(86,94)$ & $94(90,95)$ & $92(89,94)$ \\
\hline \multicolumn{4}{|l|}{ White matter } \\
\hline No injury & $86(81,89)$ & $86(79,93)$ & $92(76,94)$ \\
\hline Mild injury & $83(73,88)$ & $80(78,90)$ & $81(67,89)$ \\
\hline $\begin{array}{l}\text { Moderate/ } \\
\text { severe injury }\end{array}$ & $91(86,94)$ & $94(87,95)$ & $91(87,94)$ \\
\hline \multicolumn{4}{|l|}{ Basal ganglia } \\
\hline No injury & $84(79,89)$ & $82(79,92)$ & $85(72,92)$ \\
\hline Mild injury & $84(73,90)$ & $80(74,90)$ & $81(74,89)$ \\
\hline $\begin{array}{l}\text { Moderate/ } \\
\text { severe injury }\end{array}$ & $90(86,94)$ & $94(90,95)$ & $92(89,94)$ \\
\hline \multicolumn{4}{|l|}{ Thalamus } \\
\hline No injury & $85(79,89)$ & $86(79,93)$ & $85(78,92)$ \\
\hline Mild injury & $83(73,90)$ & $79(76,89)$ & $79(70,89)$ \\
\hline $\begin{array}{l}\text { Moderate/ } \\
\text { severe injury }\end{array}$ & $90(86,94)$ & $94(90,95)$ & $92(89,94)$ \\
\hline \multicolumn{4}{|l|}{ Brainstem } \\
\hline No injury & $85(80,90)$ & $86(79,92)$ & $85(78,91)$ \\
\hline Mild injury & $84(73,91)$ & $80(74,91)$ & $81(74,90)$ \\
\hline $\begin{array}{l}\text { Moderate/ } \\
\text { severe injury }\end{array}$ & $87(86,93)$ & $94(90,95)$ & $91(89,94)$ \\
\hline
\end{tabular}

monitoring during rewarming and normothermia were more consistently $6 \mathrm{~h}$. We analyzed the data using the percentage of time of the monitoring period to account for the different absolute monitoring durations. Second, tests for reproducibility in MRI interpretation were not performed in this singleinstitution study. MRI analyses were qualitative, which is generally considered to be less sensitive than quantitative analyses. Specific MRI findings as a function of postnatal age were not evaluated. It is possible that neurologic injury on MRI reflected prenatal insults and that cardiovascular regulation was worse in these patients than in those with less injury. Third, MRIs were obtained within the first $2 \mathrm{wk}$ of life. Although early MRI evidence of brain injury correlates to poor motor outcomes or death (11), long-term outcome data were not available for our study. Fourth, the effects of vasoactive infusions or seizures on autoregulation were not examined. The impact of vasopressors on autoregulation in neonatal HIE is unclear, although phenylephrine did not affect autoregulation in a neonatal swine model of HIE (10). Finally, an alternative measure of CBF, such as transcranial Doppler, was not used to validate HVx, because continuous Doppler over 3-4 d is not feasible in neonates. Nonetheless, HVx correlates with intracranial 
a

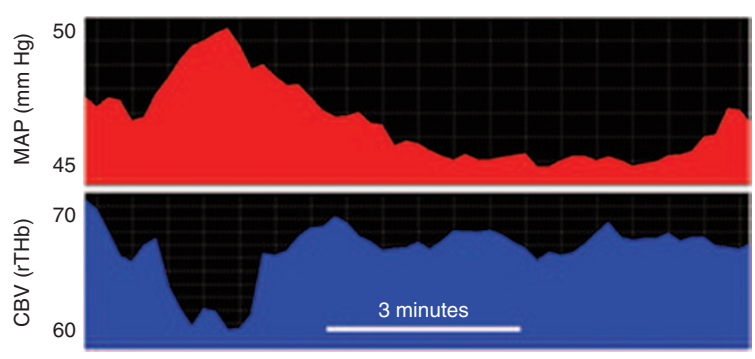

C
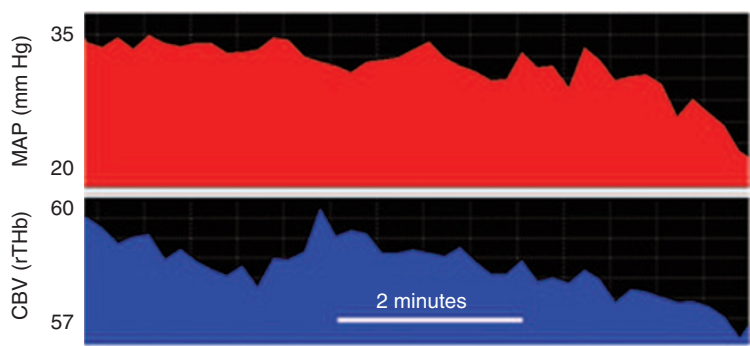

e

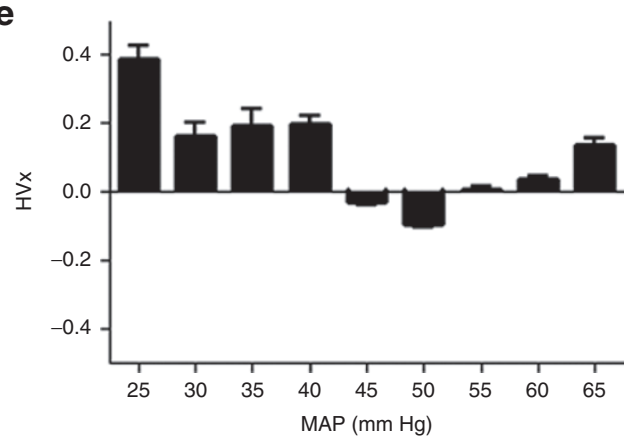

b

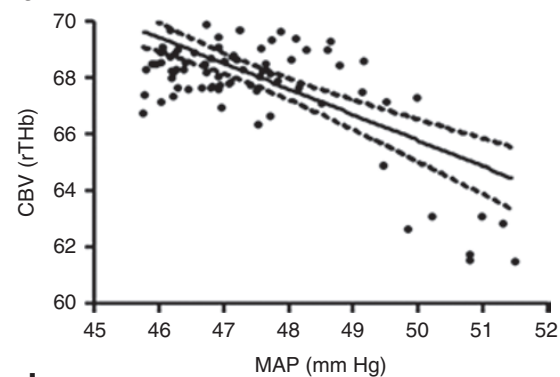

d

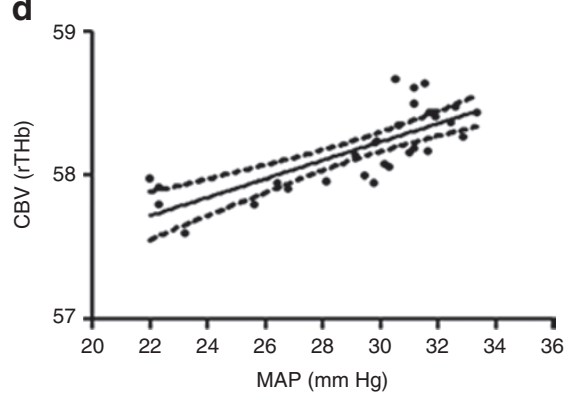

Figure 5. Hemoglobin volume index $(\mathrm{HVx})$ calculation in a neonate with hypoxic-ischemic encephalopathy. (a,b) When mean arterial blood pressure (MAP) (red) exceeded $45 \mathrm{~mm} \mathrm{Hg}$, MAP negatively correlated with cerebral blood volume (CBV (blue), or the relative total hemoglobin (rTHb) measured by near-infrared spectroscopy). This negative correlation yielded an $\mathrm{HVx}$ of -0.29 , indicating pressure-reactive vasoreactivity with functional autoregulation. The linear regression line is illustrated $(E(Y)=111.5-0.91 X ; 95 \%$ confidence interval for slope: $-1.18,-0.66 ; P<0.0001)$. (c, d) When MAP was $<35 \mathrm{~mm} \mathrm{Hg}$, MAP and CBV positively correlated. This resulted in an $\mathrm{HVx}$ of 0.12 , indicating pressure-passive vasoreactivity with impaired autoregulation. The linear regression line is illustrated $(E(Y)=56.3+0.06 X ; 95 \%$ confidence interval for slope: $0.04,0.08 ; P<0.0001)$. (e) Six hours of HVx monitoring. $H V x$ was sorted into 5-mm Hg bins of MAP. Optimal MAP (MAP ${ }_{\text {OPT }}$ ) was identified at the HVx nadir and represents the range of MAP with most robust vasoreactivity. This patient's MAP ${ }_{\text {OPT }}$ was $50 \mathrm{~mm} \mathrm{Hg}$. Data in panels $\mathbf{b}$ and $\mathbf{d}$ are shown with linear regression lines and $95 \%$ confidence intervals. Data in panel $\mathbf{e}$ are shown as means with SDs.

pressure-derived autoregulation measurements in patients (3), HVx identified the limits of autoregulation determined by laser-Doppler in a swine model of $\operatorname{HIE}(9,10)$, and HVx was validated against transcranial Doppler in identifying $\mathrm{MAP}_{\mathrm{OPT}}$ during cardiopulmonary bypass (21).

In conclusion, blood pressure maintenance within or above $\mathrm{MAP}_{\mathrm{OPT}}$ was associated with decreased neurologic injuries in neonates with HIE. HVx monitoring could enable clinicians to target optimal hemodynamic ranges for individual patients to support autoregulation and prevent secondary brain injury. Future clinical studies are indicated to further evaluate the utility of HVx in neonatal HIE.

\section{METHODS}

This study was approved by the Johns Hopkins University Institutional Review Board, and written informed consent was obtained from the parents. Between September 2010 and April 2012, neonates with HIE who were admitted to the Johns Hopkins Neonatal Intensive Care
Unit for therapeutic hypothermia were screened. To be eligible for the study, the patient's parent had to speak English or Spanish (the languages available for the consent forms), and the attending neonatologist had to agree to enroll the neonate. Eligibility criteria included gestational age $\geq 35 \mathrm{wk}$, birth weight $\geq 1,800 \mathrm{~g}$, initiation of cooling before $6 \mathrm{~h}$ of age, and an arterial blood pressure cannula. Criteria for HIE were based on the National Institute of Child Health and Human Development Neonatal Research Network's clinical trial of hypothermia in neonatal HIE (22) and included a blood gas obtained from the umbilical cord or in the first hour of life with $\mathrm{pH}<7.15$ or base deficit $>10 \mathrm{mmol} / \mathrm{l}$, and moderate-to-severe encephalopathy. If a blood gas was unavailable, an acute perinatal event, 10-min Apgar score $<5$ or assisted ventilation for $\geq 10 \mathrm{~min}$ after birth, and moderate-to-severe encephalopathy were required to diagnose HIE. Neonates without arterial blood pressure cannulae or who had congenital anomalies or coagulopathy with active bleeding that could make cooling unsafe were ineligible for the study.

\section{Clinical Care}

Clinical care was determined by the clinical team and per Neonatal Intensive Care Unit protocol. Neonates received whole-body hypothermia with a cooling blanket (Mul-T-Blanket Hyper/Hypothermia Blanket and Mul-T-Pad Temperature Therapy Pad; Gaymar 


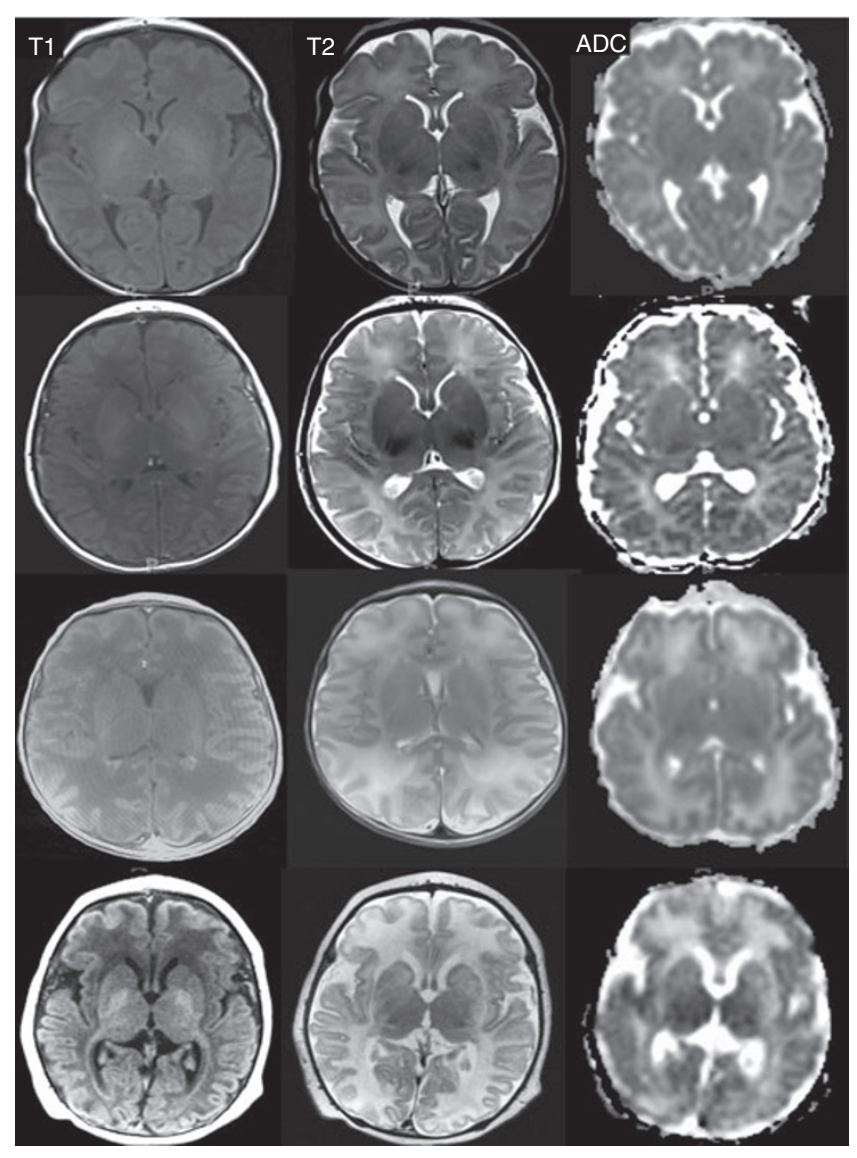

Figure 6. Axial T1-weighted (first column) and T2-weighted (second column) images and apparent diffusion coefficient maps (ADC, third column) of four neonates with no (first row), mild (second row), moderate (third row), or severe (fourth row) injury. T1 and T2 signals increased in the cortex, basal ganglia, thalami, and posterior limb of the internal capsule with greater injury. With worsening white matter injury, the T2 signal increased, and the gray-white matter differentiation became less distinct. Apparent diffusion coefficient maps confirmed the injuries, particularly in the white matter, as signal increased with greater injury.

Medi-Therm III; Gaymar Industries, Orchard Park, NY) to maintain a rectal temperature of $33.5 \pm 0.5^{\circ} \mathrm{C}$ for $72 \mathrm{~h}$. Neonates were rewarmed over $6 \mathrm{~h}$ (goal $\left.0.5^{\circ} \mathrm{C} / \mathrm{h}\right)$ to normothermia $\left(36.5^{\circ} \mathrm{C}\right)$. Hemodynamic goals were determined by the clinical team. Neonates who required vasoactive medications were given dopamine followed by dobutamine, epinephrine, or milrinone infusions as necessary. Sedation was provided with morphine, fentanyl, or hydromorphone infusions and boluses. Neonates received full montage electroencephalograms during hypothermia and after rewarming and continuous amplitude-integrated electroencephalograms monitoring (Brainz BRM3 Monitor or CFM Olympic Brainz Monitor, Natus Medical, San Carlos, $\mathrm{CA}$ ) during hypothermia, rewarming, and the first $6 \mathrm{~h}$ of normothermia. Phenobarbital was administered for electrographic or clinical seizures. Fosphenytoin, levetiracetam, or topiramate were added for persistent seizures. Head ultrasounds were obtained upon Neonatal Intensive Care Unit admission and after rewarming. Clinicians could view the blood pressure and $\mathrm{rSO}_{2}$, but they were blinded to $\mathrm{HVx}$. Clinical variables, including vital signs and laboratory measurements, were extracted from a replicated database of the electronic medical record. Clinical histories were obtained by chart reviews.

\section{Autoregulation Monitoring}

Bilateral, adhesive, neonatal cerebral oximetry probes (INVOS; Covidien, Boulder, CO) were placed on the patients' foreheads. Arterial blood pressure from the patient monitor (GE Marquette,
Garnerville, NY) and NIRS signals were synchronously sampled at $100 \mathrm{~Hz}$ and processed with an analog-to-digital converter (DT9804; Data Translation, Marlboro, MA) and bedside computer using ICM+ software (Cambridge Enterprises, Cambridge, UK) $(8-10,23,24)$. Artifacts in the NIRS and MAP signals (e.g., arterial line flushes) were manually removed, and data comprising $<1 \%$ of the recording period were excluded as an additional measure to remove artifacts (23).

HVx was calculated with a continuous, moving correlation coefficient between MAP and rTHb (a surrogate measure of CBV obtained by NIRS (8-10)). Consecutive, paired, 10-s averaged values from 300 -s duration were incorporated into each calculation, utilizing 30 data points for each HVx calculation (24). HVx ranges from -1 to +1 . Negative or near-zero $H V x$ represents functional vasoreactivity (and therefore intact autoregulation) because MAP and CBV are either negatively correlated or are not correlated. When blood pressure decreases and vasoreactivity becomes impaired, HVx becomes positive and approaches +1 because MAP and CBV positively correlate (8-10). HVx values for the right and left sides were averaged and sorted into $5-\mathrm{mm} \mathrm{Hg}$ bins of MAP to generate bar graphs. The $\mathrm{MAP}_{\mathrm{OPT}}$ in each time period (hypothermia, rewarming, and first $6 \mathrm{~h}$ of normothermia) was identified as the bin with the most negative HVx when the bar graph showed a trend of increasing index values as MAP deviated from this nadir (3) (Figure 5). Two physicians (J.K.L. and M.M.G.), who were blinded to the patient's history and MRI results, independently interpreted the HVx bar graph. Both physicians had to agree on a patient's $\mathrm{MAP}_{\mathrm{OPT}}$ to include the patient in the analysis of $\mathrm{MAP}_{\mathrm{OPT}}$ and neurologic injury.

\section{Magnetic Resonance Imaging}

Neonates received brain MRIs 3-7 d after completion of hypothermia on a 1.5-Tesla Magnetom Avanto (Siemens AG, Erlangen, Germany). All neonates received sequences with T1-weighted (T1-W), T2-weighted (T2-W), and diffusion tensor imaging. Two pediatric neuroradiologists (A.T. and T.H.) with 5 and $15 \mathrm{y}$ of dedicated pediatric neuroradiology experience evaluated the MRIs in consensus. Injury was graded as none, mild, moderate, or severe in paracentral gyri, white matter (including posterior limb of the internal capsule), basal ganglia, thalamus, and brainstem. These regions are associated with motor impairment or death in HIE (11). Qualitative evaluation for injury grading was based on the severity of signal alterations on T1-W, T2-W, and diffusion-weighted imaging (derived from the diffusion tensor imaging data (25)). Increasing T1 and T2 signals in the cortex, basal ganglia, posterior limb of the internal capsule, and thalami represented more severe injury. Increased T2 signal and loss of gray-white matter differentiation identified greater white matter injury. Increased signal in the apparent diffusion coefficient maps confirmed the presence of injury (Figure 6). The radiologists were blinded to the patients' HVx, blood pressures, and clinical histories.

\section{Statistical Analysis}

Descriptive summary statistics were conducted with SAS v9.2 (SAS Institute, Cary, NC), and graphs were generated with GraphPad Prism (v5.03; GraphPad Software, La Jolla, CA). Data are reported as means with SD or medians with IQR when appropriate. Neurologic outcomes in each anatomic region were categorized as no, mild, or moderate/severe injury. Right and left $\mathrm{rSO}_{2}$ values were averaged to analyze the relationship between $\mathrm{rSO}_{2}$ and injury. Time was analyzed as the percentage of the autoregulation monitoring period obtained during hypothermia, rewarming, or normothermia.

\section{ACKNOWLEDGMENTS}

We are grateful to Claire Levine for her editorial assistance.

\section{STATEMENT OF FINANCIAL SUPPORT}

This project was supported by research grants from Covidien (Boulder, CO; to J.K.L.), the Thomas Wilson Sanitarium for Children of Baltimore City research foundation (Baltimore, MD; to J.K.L.), the American Heart Association (Dallas, TX; to J.K.L.), the International Anesthesia Research Society (San Francisco, CA; to J.K.L.), National Institutes of Health (NIH) grants NS060703 (Bethesda, MD; to R.C.K.) and HD070996 (to F.J.N.). 


\section{REFERENCES}

1. Graham EM, Ruis KA, Hartman AL, Northington FJ, Fox HE. A systematic review of the role of intrapartum hypoxia-ischemia in the causation of neonatal encephalopathy. Am J Obstet Gynecol 2008;199:587-95.

2. Shankaran S, Pappas A, McDonald SA, et al.; Eunice Kennedy Shriver NICHD Neonatal Research Network. Childhood outcomes after hypothermia for neonatal encephalopathy. N Engl J Med 2012;366:2085-92.

3. Zweifel C, Castellani G, Czosnyka M, et al. Noninvasive monitoring of cerebrovascular reactivity with near infrared spectroscopy in head-injured patients. J Neurotrauma 2010;27:1951-8.

4. Aries MJ, Czosnyka M, Budohoski KP, et al. Continuous determination of optimal cerebral perfusion pressure in traumatic brain injury. Crit Care Med 2012;40:2456-63.

5. Brady KM, Lee JK, Kibler KK, et al. The lower limit of cerebral blood flow autoregulation is increased with elevated intracranial pressure. Anesth Analg 2009;108:1278-83.

6. Budohoski KP, Czosnyka M, de Riva N, et al. The relationship between cerebral blood flow autoregulation and cerebrovascular pressure reactivity after traumatic brain injury. Neurosurgery 2012;71:652-60; discussion 660-1.

7. Vavilala MS, Tontisirin N, Udomphorn Y, et al. Hemispheric differences in cerebral autoregulation in children with moderate and severe traumatic brain injury. Neurocrit Care 2008;9:45-54.

8. Lee JK, Kibler KK, Benni PB, et al. Cerebrovascular reactivity measured by near-infrared spectroscopy. Stroke 2009;40:1820-6.

9. Lee JK, Brady KM, Mytar JO, et al. Cerebral blood flow and cerebrovascular autoregulation in a swine model of pediatric cardiac arrest and hypothermia. Crit Care Med 2011;39:2337-45.

10. Lee JK, Yang ZJ, Wang B, et al. Noninvasive autoregulation monitoring in a swine model of pediatric cardiac arrest. Anesth Analg 2012;114:825-36.

11. Martinez-Biarge M, Diez-Sebastian J, Kapellou O, et al. Predicting motor outcome and death in term hypoxic-ischemic encephalopathy. Neurology 2011;76:2055-61.

12. Rasulo FA, Girardini A, Lavinio A, et al. Are optimal cerebral perfusion pressure and cerebrovascular autoregulation related to long-term outcome in patients with aneurysmal subarachnoid hemorrhage? J Neurosurg Anesthesiol 2012;24:3-8.

13. Iida K, Kurisu K, Arita K, Ohtani M. Hyperemia prior to acute brain swelling during rewarming of patients who have been treated with moderate hypothermia for severe head injuries. J Neurosurg 2003;98:793-9.

14. Shankaran S, Laptook AR, McDonald SA, et al.; Eunice Kennedy Shriver National Institute of Child Health and Human Development Neonatal
Research Network. Temperature profile and outcomes of neonates undergoing whole body hypothermia for neonatal hypoxic-ischemic encephalopathy. Pediatr Crit Care Med 2012;13:53-9.

15. Fan X, Kavelaars A, Heijnen CJ, Groenendaal F, van Bel F. Pharmacological neuroprotection after perinatal hypoxic-ischemic brain injury. Curr Neuropharmacol 2010;8:324-34.

16. Pimentel VC, Pinheiro FV, De Bona KS, et al. Hypoxic-ischemic brain injury stimulates inflammatory response and enzymatic activities in the hippocampus of neonatal rats. Brain Res 2011;1388:134-40.

17. Kusano Y, Echeverry G, Miekisiak G, et al. Role of adenosine A2 receptors in regulation of cerebral blood flow during induced hypotension. J Cereb Blood Flow Metab 2010;30:808-15.

18. Bakalova RA, Matsuura T, Kanno I. Cyclooxygenase-pathway participates in the regulation of regional cerebral blood flow in response to neuronal activation under normo- and hypercapnia. Prostaglandins Leukot Essent Fatty Acids 2002;67:379-88.

19. Pollock JM, Deibler AR, Whitlow CT, et al. Hypercapnia-induced cerebral hyperperfusion: an underrecognized clinical entity. AJNR Am J Neuroradiol 2009;30:378-85.

20. Pryds O, Greisen G, Lou H, Friis-Hansen B. Vasoparalysis associated with brain damage in asphyxiated term infants. J Pediatr 1990;117(1 Pt 1):11925.

21. Blaine Easley R, Kibler KK, Brady KM, et al. Continuous cerebrovascular reactivity monitoring and autoregulation monitoring identify similar lower limits of autoregulation in patients undergoing cardiopulmonary bypass. Neurol Res 2013;35:344-54.

22. Shankaran S, Laptook AR, Ehrenkranz RA, et al.; National Institute of Child Health and Human Development Neonatal Research Network. Whole-body hypothermia for neonates with hypoxic-ischemic encephalopathy. N Engl J Med 2005;353:1574-84.

23. Gilmore MM, Stone BS, Shepard JA, Czosnyka M, Easley RB, Brady KM. Relationship between cerebrovascular dysautoregulation and arterial blood pressure in the premature infant. J Perinatol 2011;31: 722-9.

24. Brady K, Joshi B, Zweifel C, et al. Real-time continuous monitoring of cerebral blood flow autoregulation using near-infrared spectroscopy in patients undergoing cardiopulmonary bypass. Stroke 2010;41: 1951-6.

25. Liauw L, van der Grond J, van den Berg-Huysmans AA, Palm-Meinders IH, van Buchem MA, van Wezel-Meijler G. Hypoxic-ischemic encephalopathy: diagnostic value of conventional MR imaging pulse sequences in term-born neonates. Radiology 2008;247:204-12. 